Canadian Oncology

Nursing Journal

Revue canadienne

de soins infirmiers

en oncologie

Volume 27, Issue 2 • Spring 2017

elSSN: 2368-8076 


\title{
Writing toward well-being: A qualitative study of community-based workshops with breast cancer survivors
}

\author{
by Roanne Thomas, Wendy Gifford, and Chad Hammond
}

\begin{abstract}
Transitioning to breast cancer survivorship can be challenging, yet there are few community-based supports. Writing is a promising psychosocial intervention, but most studies have evaluated independent writing. In contrast, our qualitative study ( $n=12)$ explored women's experiences in a community-based workshop. The analysis of workshop recordings, journals, and interviews resulted in three themes: (a) Sharing in safe spaces, (b) Seeking permission and balance, and (c) Fear and uncertainty. The themes document unmet needs related to the emotional impact of breast cancer, as well as the potential of community-based writing to enhance well-being. Such programs may address gaps in cancer survivorship care by providing safe spaces for emotional expression, while supporting participants in the crafting of new narratives focused on well-being.
\end{abstract}

\section{INTRODUCTION}

$\mathrm{T}_{\mathrm{T}}^{\mathrm{h}}$ he five-year breast cancer survival rate is now 88\% in Canada (Canadian Cancer Statistics, 2015). While this represents outstanding medical advances, it presents challenges for survivors. For example, psychosocial and rehabilitative needs related to ongoing pain or lymphedema may arise. Posttreatment transitions also involve changing roles within families, the work environment, and the community (Mackenzie, 2014; Pelusi, 2001). Such changes must be negotiated and balanced, along with the demands of maintaining physical and psychosocial well-being. All of these domains have been identified in seminal survivorship documents (Howell et al., 2009; The Institute of Medicine and National Research Council, 2005), and are featured in recent conceptualizations of distress

\section{ABOUT THE AUTHORS}

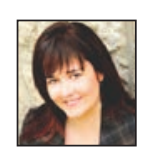

Corresponding Author: Roanne Thomas, PhD, Full Professor, School of Rehabilitation Sciences, Faculty of Health Sciences, University of Ottawa, 451 Smyth Road (RGN Room 3068), Ottawa, ON, K1H 8M5

T: 613-562-5800 (8645), F: 613-562-5428;

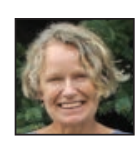
Email: roanne.thomas@uottawa.ca

Wendy Gifford, PhD, Associate Professor, School of Nursing, Faculty of Health Sciences, University of Ottawa, 451 Smyth Road (RGN Room 1118), Ottawa, ON K1H 8 M5

Email: wgifford@uottawa.ca

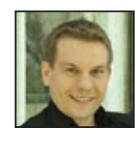

Chad Hammond, PhD, Postdoctoral Fellow, School of Rehabilitation Sciences, Faculty of Health Sciences, University of Ottawa, 451 Smyth Road (RGN Room 1125), Ottawa, ON $\mathrm{K} 1 \mathrm{H} 8 \mathrm{M5}$

Email: chammond@uottawa.ca

https://doi.org/10.5737/23688076272178185
(Bultz \& Johansen, 2011; Holland \& Bultz, 2007; Waller, Groff, Hagen, Bultz, \& Carlson, 2012) along with the need for person-centred care. Post-treatment is now widely acknowledged as a critical transition for women, as they move from treatment to reintegrating into a satisfying life (Fitch et al., 2009).

A key recommendation for survivorship services (Howell, Hack, Oliver, Chulak, Mayo, Aubin, \& Tompson, 2011) is to provide "transition support to extended survivorship" through outreach, community programs, and rehabilitation. However, pan-Canadian practice guidelines for adults indicate that "there is reasonable evidence that psychosocial and supportive care needs are under-addressed" (Howell et al., 2009; Howell, Hack, Oliver, Chulak, Mayo, Aubin, Chasen, et al., 2011). As a specific example, Thompson et al. (2014) in their study of post-treatment care demonstrate that only $49 \%$ of breast cancer survivors who were within one to five years of diagnosis felt their psychological and spiritual needs were met after treatment. Another study of 1,323 adult cancer survivors reports that more than $50 \%$ demonstrated a need for support 6 months post-diagnosis, with 37\% experiencing "moderate to high-level" unmet needs related to fear, fatigue, distress, and uncertainty, as well as work and sexuality (Boyes, Girgis, D’Este, \& Zucca, 2012). While distress has been recognized as the "sixth vital sign" in cancer care, survivors seem to have limited access to psychosocial interventions (Bultz \& Johansen, 2011). Over the long term, cancer survivorship care must address various spheres, including the individual, family, and community, as survivorship is a "dynamic, lifelong process." (Pelusi, 2001). While supportive care often concludes with the completion of acute care, cancer survivors' concerns extend well beyond that period of time (Thomas-MacLean, 2004a). Community-based creative interventions, such as writing, can be tailored to participants' needs and may address some of the challenges of survivorship.

A growing body of research finds creative engagement is "personally meaningful", and contributes to good health and well-being (Camic, 2008; Cox et al., 2010; Sonke, Rollins, Brandman, \& Graham-Pole, 2009; Stuckey \& Nobel, 2010). Alongside the increasing interest in arts and health, there is a growing awareness of the potential for arts-based research and arts-based knowledge translation (KT) (Barone \& Eisner, 2012; Knowles \& Cole, 2008; Rieger \& Schultz, 2014) to contribute to cancer survivorship strategies. However, the systematic exploration of the efficacy of a wide range of creative arts-based practices, such as visual arts and writing, is relatively recent and under-explored (Rieger \& Schultz, 2014).

Generally, it is well-recognized that engagement with creative processes can enhance emotional states, as well as 
general overall health (Stuckey \& Nobel, 2010). In a review of arts and health research, Stuckey and Nobel (2010) cite several RCTs that demonstrated improved outcomes for intervention groups (versus controls) associated with the arts, including writing. Studies included participants with chronic illnesses, such as HIV and fibromyalgia and noted improvements include decreased distress, pain, fatigue, and healthcare usage. Creative processes (e.g., writing, and visual arts such as painting) have also been shown to reduce symptoms of depression, stress and fatigue, while enhancing well-being in cancer patients (Haltiwanger, Rojo, \& Funk, 2011; Visser \& Op'T Hoog, 2008). A systematic review of RCTs and various creative arts therapies found reduced anxiety, depression, and pain, as well as improved quality of life (QOL) with medium to large effect sizes across 27 studies involving 1,576 cancer patients (Puetz, Morley, \& Herring, 2013). While this review demonstrates the effectiveness of arts-based approaches, most of the studies utilized music therapy, indicating that writing is understudied.

Another limitation of these studies is that most examined hospital-based interventions (Stuckey \& Nobel, 2010). The authors note that community-based interventions have been neglected and recommend that future research occur there and within groups. Group-based interventions incorporating creative practices have resulted in decreased distress, improvements in coping, and improved mental health (Monti et al., 2006; Rosedale, 2009; Visser \& Op'T Hoog, 2008). For example, a community-based study with breast cancer survivors showed improvements in multiple outcomes, including improved QOL, fatigue, and posttraumatic stress (Lu, Zheng, Young, Kagawa-Singer, \& Loh, 2012). Research also demonstrates that group activities may help to empower participants, enhance coping skills, and improve mood and QOL (Haltiwanger et al., 2011; Luzzatto \& Gabriel, 2000).

One specific approach to writing that has been widely studied and has resulted in improvements to emotional well-being is the "expressive writing" (EW) process (developed by Pennebaker). A recent systematic review of EW for cancer patients (1986-2012) included 13 studies with an experimental trial design (Merz, Fox, \& Malcarne, 2014). While these show promising results (e.g., beneficial effects on sleep, pain, and other psychological and physical symptoms), there are several limitations to the studies and EW itself. First, Merz et al. (2014) note that EW is completed independently with minimal instruction and there are indications that the usual number of writing sessions (one to four) involved may be insufficient. Likewise, Nicholls (2009) asserts that EW and associated outcomes are limited because the intervention is restricted to a few, short sessions of independent writing with only brief instructions for participants (Nicholls, 2009). Second, none of the studies included an in-depth, qualitative analysis of participants' writing. Merz et al. (2014) assert that analysis of their writing could provide data about the mechanisms of writing that work and for whom. These data could inform intervention design. Further, qualitative data could increase knowledge about EW's effects on personal growth or 'meaning making', which may enhance psychosocial well-being, but are not easily measured (Merz et al., 2014). Third, only one study allowed participants to tailor the intervention (i.e., to determine the topic of their writing); that study (Jensen-Johansen et al., 2012) produced the most significant findings of the 13 studies included, suggesting that a flexible writing intervention may have the greatest impact (Merz et al., 2014). Finally, the authors also noted the "real world" gap of EW (Merz et al., 2014). Research has shown that writing with a group of supportive peers and an experienced mentor may result in benefits for those who have not found the task-oriented approach of EW to be beneficial (Nicholls, 2009). In contrast to EW, the increasingly prevalent approach advocated by Nicholls involves a combination of independent and group-based activities.

We delivered a community-based intervention that addressed some of the limitations of previous research, as it incorporated individual and group activities, and allowed for flexibility and adaptations to guidelines, as well as reading and reflexivity exercises. That is, participants engaged in some distancing from the initial writing, as well as progressive tasks such as explorations of point-of-view and other revisions. Our writing intervention was community-based and included the support of a professional writer. Thus, our intervention capitalized on the demonstrated benefits of writing, while addressing the limitations of the EW approach and associated studies.

The purpose of our study was to pilot test a creative writing intervention for breast cancer survivors to qualitatively explore the potential impact of the program upon well-being. A secondary aim was to qualitatively document breast cancer survivorship transitions and issues conveyed through the participants' writing, as well as the use of other methods. These are overlapping objectives and it would be challenging to discuss them in isolation. The emphasis of this article is upon the women's experiences of writing and the workshops.

\section{METHODS}

In order to explore the potential impact of the intervention and document transitions/issues, our study used an interpretive description design (Thorne, 2008). Qualitative data were generated through the use of journals, visual methods (i.e., the production and photographing of participants' collages), as well as surveys and telephone interviews with participants. In addition, the writing workshops were audio-recorded and transcribed verbatim.

The research and our intervention also drew upon well-established theoretical frameworks developed within the context of knowledge surrounding illness narratives (Bury, 1982; Frank, 1995; Malchiodi, 2013; Sinding \& Wiernikowski, 2008; Thomas-MacLean, 2004b). In short, while the precise mechanism that instigates the varied health benefits of writing and other arts-based practices is unknown, scholars theorize that illness disrupts life narratives. Associated distress may be alleviated through processes that facilitate meaning-making within specific contexts (Malchiodi, 2013). For instance, culturally dominant illness narratives do not provide opportunities for women to query purely positive survivorship ideologies and women may find the label of survivor limiting, as it does not allow for the expression of fear or pain (Malchiodi, 2013; Thomas-MacLean, 
2004b). Reflective writing among peers with shared experiences can provide a safe space to express emotions and adapt illness narratives (Collie, Bottorff, \& Long, 2006).

Our writing intervention was delivered in a compressed workshop format of 14 hours delivered over 2 days $(7$ hours per day). The two workshops were scheduled two weeks apart to allow for independent writing. Content, tools, and methods of delivery were developed in partnership with a professional writer whose approach incorporated an embodied orientation to writing; for instance, participants were invited to complete a mindfulness exercise involving deep-breathing and reflection upon embodiment (Thomas-MacLean, 2005) prior to beginning some of the writing exercises. Participants were also provided with journals and a writing guide.

\section{Participants and setting}

After receiving approval from our university's Research Ethics Board, we commenced participant accrual, advertising our study through a community-based cancer survivorship centre in Ottawa, Ontario, which hosted the workshops. Twelve women who had experienced breast cancer completed the workshops. Participants were 43 to 75 years of age, with a mean age of 54 years, and 6 months to 9 years post-diagnosis (mean of 2 years). Eight of 12 participants reported they had previously discussed their experiences of breast cancer within a support group and/or with a health professional. The women completed 6-17 journal entries (mean of 11 journals) and wrote from 13 to 41 pages (mean of 23 pages). Eleven of the 12 participants completed and shared collages.

\section{Analysis}

All workshop discussions were audio-recorded, including whole group discussions and those conducted in smaller groups. Verbatim transcripts were checked against the workshop sound files by a research assistant. Since the telephone interviews drew upon participants' responses to open-ended surveys about the workshops and were intended to simply amplify the written survey data, the interviews were not recorded, but interview notes were triangulated with the corresponding survey questions. Participants' collages were photographed, while journal entries were scanned and saved as PDFs. All data were then uploaded for analysis into NVivo 10. Transcripts, journal entries, survey responses, and interview notes were read holistically and line by line to extract significant statements from the interviews, following established guidelines for interpretive description studies (Thorne, 2008). Significant statements were selected to generate initial codes for a schema. Resulting thematic categories were then clustered in order to illustrate predominant issues associated with survivorship transitions and the impact of the intervention. The initial coding was completed by the first author, then reviewed and analyzed further through discussions with the second and third authors.

Credibility and patterning (Leininger, 1994; Munhall \& Oiler-Boyd, 1993) - two commonly used criteria to assess the quality of analysis-were established through the comparison of multiple sources of data. For instance, the benefits of a group setting were evident in journal entries and workshop transcripts. As another example, the individual follow-up interviews provided opportunities to clarify written data from the workshop evaluations. Finally, all participants were invited to a group session during which preliminary findings were shared. Five of the women attended the session and when asked if the findings corresponded with their experiences in the program, all agreed that they did and reaffirmed the need for supportive programs with an active focus (i.e., those incorporating activities, such as writing, rather than discussion only, as in traditional support groups).

\section{RESULTS}

Three main themes emerged from the analyses of the journals, workshop surveys/interviews, and workshop transcripts. Analysis of the collages is beyond the scope of this manuscript and will be a focus of a future publication. The three themes are (a) sharing in safe spaces, (b) seeking permission and balance, and (c) fear and uncertainty. The first theme is connected to the expression of emotions (e.g., anger, distress) perceived as negative. Participants felt they were unable to share these emotions with others outside of the group. The second theme illustrates perceptions that the demands of various roles, along with illness experiences, resulted in situations where they had to actively rebalance various domains of everyday life and grant themselves permission to reflect upon cancer and its impact. The third theme conveys participants' experiences of uncertainty due to cancer and their desire to find ways to cope. Together, the themes demonstrate a need for community-based, participatory, interventions to address transitions and distress for women with breast cancer.

\section{Sharing in safe spaces}

We conceptualize space broadly: it is not simply identified as the physical location of the workshops, but expands to include materials for self-expression (e.g., journals), as well as the social context of the workshops. Construction of various safe spaces began with the first workshop and underpinned their duration. As safe spaces ground all of the processes, from writing to editing to sharing, space is foundational to all of the themes so that their order is not entirely chronological.

From the beginning of the workshops, safe spaces were created in multiple ways. Somewhat unexpectedly, participants assumed responsibility for creating a safe space early on. For example, during the introductions, one participant ${ }^{1}$ stated "I'm very, very happy to be here today and to have the opportunity to meet with other women." She demonstrated that there would be value in hearing what other women had to say about their experiences. As the introductions continued, the establishment of a safe space is illustrated by dialogue between a participant and one of the facilitators that also occurred within the first 30 minutes of Workshop 1:

${ }^{1}$ Participants were assigned pseudonyms for the interview and journal data. The group discussions are comparable to focus groups, wherein individual speakers are not usually identifiable. However, because there were some discussions held in smaller groups, participants in these discussions have been identified by their pseudonyms whenever possible. 
Participant: Well I'd like to say that during my cancer journey, I've had many positive things happen to me, but I've also had negative things happen. So certainly, I would like to speak about the negative and the positive. I wouldn't want this all to be 'rah rah rah', because everything hasn't been great for the last year. And if I feel any need to bring up something that isn't positive, I want to feel comfortable in being able to do so.

Facilitator: Good. I'm glad you raised that because absolutely not. This is not a Pollyanna workshop. You don't have to put a positive face on it. It's about your own writing.

In the example above, a safe space was created collaboratively-by the participant, who was willing to advance her needs and by the facilitator's response.

This creation of a safe space was ongoing and is reflected in a participant's comments toward the end of the first day, after writing was shared:

People are also putting into words some things that I've felt, but haven't articulated myself. It's that shared experience, I think, that it's like, 'Oh! You said it. That's what my experience was,' which I think is part of the essence of the great writing and the purpose for reading.

Another participant, reflecting on the first day, said:

One has to be able to express things that are there, but that you're not really so conscious of. The other thing is just hearing what people have to say. It's amazing to me that we can share things like that. Everything people have been saying, you know, that's amazing that they're thinking about that too... we shared so much and to be able to have that happen in a form like this-it's really meaningful. It's great.

Likewise, Bridget said: "It is comforting to be with people who have experienced what I have been through... I also like to feel that I can help people."

The second workshop began with a remark from Barbara who began by acknowledging the support she had received from another participant: "I thought about your comment on my writing all week and I thought 'What a nice thing to say.' So, thank you for that. [To the group] Her comment was so insightful, you know." Barbara's comment helped to ensure the safe space of the first workshop was maintained and acknowledged early in the second one.

During Workshop 2, Nathalie also indicated the various ways in which safe spaces could be created, whether through shared experience or through writing:

What I like about the workshops the most, is connecting with women who are in a similar situation who can understand what I'm going through without having to explain. But there's also definitely some skills and the types of writing that I've learned. Like free form writing-I never knew that existed, how to even begin trying to write poetry. So, although I'm not ready to go to a deeply emotional place, there are take-aways for me that later, I know I could utilize them to work through some of the stuff mentally.
Participants began writing in their journals at the first workshop and were invited to continue between the workshops. Despite some initial hesitation, participants felt that the journals might provide them with a safe space. Karen wrote: "Writing brings out emotions I haven't expressed." She wrote that she did not express these emotions because she wanted to protect her family from them. She noted: "I am concerned about writing them down, leaving a trace... but I gave myself permission to write out some of the bad things." This issue regarding privacy was addressed early in the workshop, as one of the facilitators explained various approaches to maintaining the safe space of the journal, such as leaving it with the facilitators between workshops and writing only in the group setting, or emphasizing the need for privacy with family members.

In a similar vein, Deborah's writing illustrates the safe space of writing. She wrote that she felt fortunate to have many supportive people in her life, but that they were not always aware of the ongoing struggles of survivorship:

I am finding it hard lately to share and relate what is going on with me, both physically and emotionally... some people assume that because I am doing really well overall, that it's the end of the story. The mental and emotional stress is significant though and some people don't realize that.

Her writing provided her with a place to raise issues that she was unable to discuss with others.

Upon reflecting on the workshops, Deborah noted in her journal: "I am grateful I made the time to attend. Grateful for what I learned. Grateful to have the opportunity to think, write, and create. And, most of all, grateful to connect with other women." Thus, safe spaces were created within the workshop setting and structure, as well the group-based sharing activities, and private explorations associated with individual, reflective writing. As the words of Karen and Deborah demonstrate, the theme of safe space is also connected to the second theme of allowing oneself permission to write.

\section{Seeking permission and balance}

Writing provided participants with permission to express emotions that they were unable to process during diagnosis and treatment. Many of the participants also felt they had to grant themselves permission to give themselves time from various roles to write. Permission was also connected to aiming for balance in their lives (e.g., between their own needs, those of family members, and work).

Several participants said they could not allow themselves to acknowledge any emotions during diagnosis and treatment. For instance, Marie spoke about having to put emotional processing on hold:

I said to myself, 'Okay. You have to do this. It's going to be shit for a year, but you have to get through it.' And then I just got up, I pulled up my boot straps, and I started to organize everything as if I wasn't going to be functional at all for a year. So, I made a will. I lined up friends and family to help my husband with my kids. I started making meal plans. I did this two weeks of mad organization before I had my surgery so that my husband didn't have to-I overpaid bills so that we had a credit account and all that stuff because I handle the finances of the house. 
Marie continued:

I had decided I was going to journal on a blog and put everything on there. I think I journaled twice and that was it! And then I did the chemo and radiation and my focus was always on the physical aspect. Now that it's finished, I'm an emotional wreck. I think everything has kind of caught up to me. . . I don't recognize myself anymore. This would never have happened, ever before-I cry at the drop of a hat. I am extremely sensitive, over-sensitive. I get very aggressive. I'm just a wreck.

Another participant expressed similar thoughts: "Just feeling the freedom to cry is very helpful to release the emotions that are bottled up... going through treatment I can say I didn't cry very often because you're trying to be strong, right?" Likewise, Susan wrote of the treatment phase in her journal: "My mind was filled with the chaotic schedule of doctors appointments, tests, and the unknown of what would be next." Barbara also said:

It took me 10 months to cry about my cancer. It took me 10 months. Finally, I trusted somebody enough. I sat there and I said 'You know, I thought I'd dealt with this.' I cried and I cried, and it was in a safe place. And I said I'm finally crying about my cancer, finally... To put yourself first—-that's something for women that's very hard because we have so many people we put before us.

For participants such as Barbara, the writing and workshop participation were associated with the expression of emotion and with an opportunity to "put themselves first"—a granting of permission.

Permission was also connected to discussions of balance between self, work, and family. Nathalie noted that the end of treatment resulted in a return to her pre-cancer "busy life":

I went through all the treatment. I had a mastectomy and chemo and radiation, the whole works, and now I'm back to full-time work... Now I'm back at work and everything's getting really busy again, and I think I've got to find an outlet. I do run and that's great, but I need to find something else to manage my stress. Because I don't want to go back to that really busy life I had. I feel like I'm there again. So hopefully this will help with managing my stress and getting everything out.

Similarly, another participant said:

I love to write, but I never do it... what I've learned is: I have to put myself first and that's been very hard for me because I have children, I have grandchildren, I have had a responsible job. Everybody else comes first except me... So, I realize, by reading what I wrote, that I need to have the time. I need to spend the time to go to the cottage. I need to look at that lake. This is all about 'I, I, I,' of course. When I do that, I feel a little bit guilty because I want to write 'We,' but it was all 'I' and I thought, 'That's really good.' Because I still find it hard.

When discussing her writing, another participant illustrated the connections between achieving balance, prioritizing her own needs, and writing:
My writing was kind of like a dialogue with my father... it was like him writing a story to me... his words of wisdom were 'Life is too short. Look forward to your time alone. What do you want for yourself? Allow yourself time to do what you want to do.'

Other participants also wrote in their journals about seeking permission to express emotions and to prioritize selfcare. Susan wrote: "Time to reflect and think about me. Will it disappoint others?" She later continued her writing: "Pause. Slow down. Set priorities. Re-evaluate. Think. Choose... I need to focus on myself, to focus on healing... something more than just physical—emotional and spiritual healing, as well." Likewise, Barbara wrote about taking a broad approach to healing: "In order to smile, laugh, and be at peace, I need to have support, comfortable people around me, and a peaceful environment... I will be selfish in protecting myself from negative situations." Similarly, Nathalie wrote: "Need balance in my life. Physical, mental, emotional, and social balance. Priority lists. Just say no. More of what I want to do. This is what I am striving for. This is what I am seeking. Can I do it?” She wrote that cancer had provided her with an opportunity to re-evaluate what was important, but that after being back to work for 2.5 years, she wrote:

I find myself getting caught up in the stress of trying to accomplish too much in one day. I don't want this lifestyle. Have to get smart about my time... Prioritize me... I've committed to taking 15 minutes for myself each day. I can nap, write, listen to music, etc.

Bridget wrote: "I am trying to get rid of the 'shoulds' in my life." Sandra wrote: "Give yourself permission to have fun, fun, fun. No more coulda, shoulda, woulda."

Although recognized as valuable, permission to self-care was often difficult to grant. Marie wrote about a day when she felt fatigued and unable to accomplish a list of tasks she had set for herself:

Keep feeling I am not doing what I am supposed to be. Not cleaning the house. Not de-cluttering. Not organizing for school. Not teaching the kids to read. Not training the dog. Not cooking healthy meals. Not exercising enough. Not drinking enough water.

Participants also showed that patient education can be problematic, rather than positive. Barbara wrote: "I am always thinking of the right type of food, the correct form of exercise. I am ready to forget all of this and take up new activities not related to cancer."

In summary, participants indicated that they felt they needed permission to express emotions and that there had been few opportunities to do so during treatment. Writing and its discussion provided participants with permission to express emotions and to take time from caring for others to do so. Given gender norms, this is not an easy task, as the women show. Further, while caring for self was viewed as positive, it also resulted in feelings of pressure to manage the possibility of recurrence, which was revealed as an ongoing source of anxiety and uncertainty. 


\section{Fear and Uncertainty}

Fear and uncertainty have temporal elements, as the women's discussions and journal entries demonstrate and were related to the cause of cancer and involved reflecting backward in time. Fear and uncertainty were also connected to the possibility of recurrence, underlined by ongoing tests and waiting for results. Fear was, therefore, connected both to the present and to the future. Writing assuaged some of these fears.

The temporal element of fear and uncertainty is reflected in Bridget's writing about the cause of cancer: "Why did I get cancer? What did I do wrong... if you can figure out what caused the cancer, you can discontinue that behaviour in the future and it won't happen again." She continued writing for three pages, wondering if the cause was hormone replacement therapy or exposure to pesticides.

Susan showed how this type of anxiety was connected to her present experiences of treatment: "Fear, worry, anxiety, uncertainty, lost, hopeless, alone, sad-just some of the words to describe my feelings when days are bad and the treatment is overwhelming... Nobody knows what tomorrow brings, what treatment will hold the cancer back." Marie noted that during treatment, she needed a health professional to tell her that she was "going to be okay." She said that nobody had told her that and while she realized it might be "impossible" for a doctor to say this, it would have alleviated much distress during the immediacy of treatment and during her present recollections of that time.

Fear was also reflected in participants' words about the future. One participant said:

My big fear is that I might die... I don't want to lose me. I don't want to be lost... [the image I wrote about] had all these connotations about family and people that I've lost and my own fear of being lost.

Karen wrote: “It's okay to be scared; we fear what we don't know. And, in this case, what we don't know, could be death. Nothingness. People left behind. I'm afraid. I'm strong." In another entry, she continued: "I'm afraid. I can't work. I fear recurrence. I fear more treatments. I fear side-effects... I don't know how much to tell people about what is going on with me." Similarly, Nathalie wrote about uncertainty and fear, using the metaphor of the "Las Vegas of life." She wondered "What do I do about fears of recurrence?" Likewise, Bridget wrote: "The biggest thing I have to deal with is the anxiety of a recurrence. I even hate to write anything about it because I don't want to focus on it. However, I have to deal with it." She was waiting for test results at the time of her writing, as was another participant, Deborah, who wrote: "I guess this is what cancer survivors have to go through. It is always in the back of our minds." However, Bridget's last entry was a description of a water fountain, getting stronger: "a spigot flush with the ground that starts to bubble and then gets stronger and stronger... going through all the colours of the rainbow." For her, this image of water represented hope and both might be "low" or "high", but "available when we need to access it."
While writing provided a safe space and permission to express fear, participants also wrote about emerging strengths, as Bridget's writing about the fountain shows. Like Bridget, Barbara wrote: "I am thinking about a future again. I can participate and still contribute. I can learn and absorb information. I am no longer paralyzed by fear."

To summarize, fear and uncertainty were associated with the past for participants who had completed treatment, largely through reflections about the causes of cancer. However, fear and uncertainty were also associated with the present for those still in treatment. For most participants, fear and anxiety overshadowed future considerations of life after cancer treatment, but they also wrote hopefully about acceptance and their strengths.

\section{DISCUSSION}

Our research supports the growing body of evidence regarding cancer survivors' unmet needs during transitions to survivorship (Boyes et al., 2012; Fitch et al., 2009; Thompson et al., 2014). Our data reinforce the idea that survivorship is a "dynamic, lifelong process" (Pelusi, 2001), but also demonstrate gaps in care that are similarly noted in various survivorship policy documents (Howell et al., 2009). To address such gaps, educators could begin to capitalize upon the increasing recognition of arts-based approaches to survivorship through the development of modules for health professionals. Despite varying time periods since diagnosis and treatment $(6$ months to 9 years), all participants were still experiencing distress, uncertainty, and a lack of psychosocial support, such as the provision of safe spaces in which emotions could be processed and shared. With new educational options, nurses may be well-positioned to create such spaces.

Participants indicated that enduring survivorship issues, such as the ones outlined above, were key reasons for joining the workshops and for writing. While participants were able to define sources of distress (e.g., existential aspects), it is not clear that these experiences are fully captured in the literature. Future research could use writing and other arts-based approaches to explore the more complex dimensions of distress qualitatively across larger samples. In the meantime, community-based programs could effectively, and at minimal expense, address some gaps in programming, particularly since survivors' fears and uncertainties do not end with the conclusion of acute care (Howell, Hack, Oliver, Chulak, Mayo, Aubin, Chasen, et al., 2011; Thomas-MacLean, 2004a). Safe spaces may provide support to express emotions left unexamined during acute care and those that may arise subsequently. Administrators of survivorship programs may wish to explore ways to create and maintain these spaces when determining program locations and approaches to unmet needs.

Our findings are also congruent with various studies indicating that arts-based interventions can enhance well-being in cancer survivors (Lu et al., 2012; Luzzatto \& Gabriel, 2000; Monti et al., 2006; Visser \& Op’T Hoog, 2008). All participants rated the program favourably and indicated that it addressed many survivorship concerns, including fear and distress. 
Participants would highly recommend the intervention to others and supported a longer program, particularly since they would have benefited from additional time to write. Yet, while there is increasing recognition of the benefits of the arts for health generally, and for writing more specifically, there are few programs in place that provide guidance for women who are interested in pursuing individual and group-based creative practices within the community. For instance, most participants had been counselled by mental health professionals and/or participated in conventional support groups and were told that writing could be helpful with survivorship transitions. However, these participants did not receive any specific guidance. As an example, one participant had purchased a journal some time before the workshops, but did not know how to begin the process of reflective writing. Participants' experiences are, thus, illustrative of a gap between research, evidence, and practice. Community-based writing programs could function as a low-cost intervention to address this gap, providing the necessary guidance and "permission" for participants to begin to enhance well-being and their quality of life. Until such programs are readily available, health professionals may wish to collect writing prompts for distribution to cancer survivors and to attain basic writing facilitation skills if they choose to recommend writing to patients.

As noted in other research (Mackenzie, 2014; Pelusi, 2001), several participants also spoke of the challenges of prioritizing self-care, such as physical and creative activities, within the context of family roles and paid work, despite being aware of the health benefits. That is, balancing self-care and self-compassion with the demands of everyday life was difficult for participants, highlighting the importance of interventions to facilitate this process. As one participant noted, she felt she had learned about the importance of balance through cancer, but was unable to maintain this after returning to work. Participants' writings and discussions show that while health promotion efforts may be successful in disseminating information about cancer prevention and recurrence, they are less successful in promoting and implementing strategies for self-care. Our data show that messages about health promotion may create distress when the engagement of target users is challenging and social context (e.g., gender norms such as those related to caregiving) is not considered. For women in transition between acute treatment and survivorship, permission must be granted, where the workshops and the writing served to legitimize time spent focused upon the self. To

\section{REFERENCES}

Barone, T., \& Eisner, E.W. (2012). Arts based research. Thousand Oaks, CA: Sage Publications.

Boyes, A.W., Girgis, A., D’Este, C., \& Zucca, A.C. (2012). Prevalence and correlates of cancer survivors' supportive care needs 6 months after diagnosis: A population-based cross-sectional study. BMC Cancer, 12, 150. doi:10.1186/1471-2407-12-150

Bultz, B.D., \& Johansen, C. (2011). Screening for distress, the 6th vital sign: Where are we, and where are we going? Psycho-Oncology, 20(6), 569-571. doi:10.1002/pon.1986 supplement such workshops, or in the absence of them, health professionals could direct attention to the various roles that women fulfill and discuss barriers to self-care while sharing information related to health promotion.

Importantly, and compared to Pennebaker's EW (expressive writing), which is completed in isolation, our data illustrate the benefits of a group-based approach to writing. All participants indicated that the group support, along with the guided writing, was helpful. Group discussions assisted with meaning-making and the re-creation of narratives to incorporate positive transitions to survivorship. The benefits of sharing were not only noted in participants' writing and in workshop evaluations, but were also discussed early in Workshop 1, suggesting the benefits of a group-based approach could be quite immediate. It is interesting to note that there is an active, traditional support group in the study setting, however participants indicated that while they wished to discuss survivorship issues, they preferred to be actively engaged and learning while doing so. They noted that traditional support groups do not provide such opportunities. This suggests there are potentially fruitful connections to be made between occupational science (e.g., meaningful occupation/activity) and other health disciplines. Fostering such connections could begin at the level of educational programming.

Despite the benefits of writing and the many implications of our research for practice, the limitations of our study do have to be acknowledged. First, a longitudinal study design could help to illuminate some of the benefits and challenges associated with writing, which can reasonably be viewed as a long-term pursuit. Secondly, participants were predominantly white, middle class, and well-educated. Writing may appeal more to such populations and our results may have been affected by the self-selection of participants who were prepared to write. However, we do note that some approaches to writing (e.g., the Amherst Writers and Artists approach) have been used successfully with marginalized populations who have had limited educational opportunities.

Despite these limitations, our research shows that a community-based writing intervention may address some of the gaps in cancer survivorship research-practice by providing safe spaces for the expression of emotions, such as fear and distress, while assisting participants to craft new narratives focused on well-being. Future research could focus on qualitatively understanding the potential long-term benefits of such meaning-making within the broad context of survivorship transitions.

Bury, M. (1982). Chronic illness as biographical disruption. Sociology of Health and Illness, 4(2), 167-182. doi:10.1111/1467-9566. ep11339939

Camic, P.M. (2008). Playing in the mud: Health psychology, the arts and creative approaches to health care. Journal of Health Psychology, 13(2), 287-298. doi:10.1177/1359105307086698

Canadian Cancer Statistics. (2015). Special topic: Predictions of the future burden of cancer in Canada. Retrieved from http://www. cancer.ca/ /media/cancer.ca/CW/cancer\%20information/ 
cancer\%20101/Canadian\%20cancer\%20statistics/CanadianCancer-Statistics-2015-EN.pdf?la=en

Collie, K., Bottorff, J.L., \& Long, B.C. (2006). A narrative view of art therapy and art making by women with breast cancer. Journal of Health Psychology, 11(5), 761-775. doi:10.1177/1359105306066632

Cox, S.M., Lafrenière, D., Brett-MacLean, P., Collie, K., Cooley, N., Dunbrack, J., \& Frager, G. (2010). Tipping the iceberg? The state of arts and health in Canada. Arts Q Health, 2(2), 109-124. doi:10.1080 /17533015.2010.481291

Fitch, M., Ristovski-Slijepcevic, S., Scalzo, K., Bennie, F., Nicoll, I., \& Doll, R. (2009). Cancer survivorship: Creating a national agenda. Cancer Oncology Nursing Journal, 19(2), 55-59.

Frank, A. (1995). The wounded storyteller: Body, illness, and ethics. Chicago, IL: University of Chicago Press.

Haltiwanger, E., Rojo, R., \& Funk, K. (2011). Living with cancer: Impact of expressive arts. Occupational Therapy in Mental Health, 27(1), 65-86.

Holland, J.C., \& Bultz, B.D. (2007). The NCCN guideline for distress management: A case for making distress the sixth vital sign. JNCCN-Journal of the National Comprehensive Cancer Network, 5(1), 3-7.

Howell, D., Currie, S., Mayo, S., Jones, G., Boyle, M., Hack, T., ... Collacutt, V. (2009). A pan-Canadian clinical practice guideline: Assessment of psychosocial health care needs of the adult cancer patient. Toronto: Canadian Partnership Against Cancer (Cancer Journey Action Group) and the Canadian Association of Psychosocial Oncology.

Howell, D., Hack, T., Oliver, T., Chulak, T., Mayo, S., Aubin, M., \& Tompson, M. (2011). A pan-Canadian practice guideline: PanCanadian guidance on organization and structure of survivorship services and psychosocial-supportive care best practices for adult cancer survivors. Canadian Partnership Against Cancer (Cancer Journey Action Group) and the Canadian Association of Psychosocial Oncology: Toronto.

Howell, D., Hack, T.F., Oliver, T.K., Chulak, T., Mayo, S., Aubin, M., ... Sinclair, S. (2011). Survivorship services for adult cancer populations: A pan-Canadian guideline. Current Oncology, 18(6), e265-281. doi:10.3747/co.v18i6.956

Jensen-Johansen, M., Christensen, S., Valdimarsdottir, H., Zakowski, S., Jensen, A.B., Bovbjerg, D., \& Zachariae, R. (2012). Effects of an expressive writing intervention on cancer-related distress in Danish breast cancer survivors-Results from a nationwide randomized clinical trial. Psycho-Oncology, 22(7), 1492-1500. doi:10.1002/pon.3193

Knowles, J.G., \& Cole, A.L. (2008). Handbook of the arts in qualitative research: Perspectives, methodologies, examples, and issues. Thousand Oaks, CA: Sage Publications.

Leininger, M. (1994). Evaluation criteria and critique of qualitative research studies. In J.M. Morse (Ed.), Critical issues in qualitative research methods (pp. 95-115). Thousand Oaks, CA: Sage Publications.

Lu, Q., Zheng, D., Young, L., Kagawa-Singer, M., \& Loh, A. (2012). A pilot study of expressive writing intervention among Chinesespeaking breast cancer survivors. Health Psychology, 31(5), 548. doi:10.1037/a0026834

Luzzatto, P., \& Gabriel, B. (2000). The creative journey: A model for short-term group art therapy with posttreatment cancer patients. Art Therapy, 17(4), 265-269. doi:1080/07421656.2000.10129764

Mackenzie, C.R. (2014). 'It is hard for mums to put themselves first': How mothers diagnosed with breast cancer manage the sociological boundaries between paid work, family and caring for the self. Social Science and Medicine, 117, 96-106. doi:10.1016/j. socscimed.2014.07.043
Malchiodi, C.A. (2013). Art therapy and health care. New York, NY: Guilford Press.

Merz, E.L., Fox, R.S., \& Malcarne, V.L. (2014). Expressive writing interventions in cancer patients: A systematic review. Health Psychology Review, 8(3), 339-361. doi:10.1080/17437199.2014.882007

Monti, D.A., Peterson, C., Kunkel, E.J., Hauck, W.W., Pequignot, E., Rhodes, L., \& Brainard, G.C. (2006). A randomized, controlled trial of mindfulness-based art therapy (MBAT) for women with cancer. Psycho-Oncology, 15(5), 363-373. doi:10.1002/pon.988

Munhall, P.L., \& Oiler-Boyd, C. (1993). Nursing research: A qualitative perspective. New York, NY: National League of Nursing.

Nicholls, S. (2009). Beyond expressive writing: Evolving models of developmental creative writing. Journal of Health Psychology, 14(2), 171-180. doi:10.1177/1359105308100201

Pelusi, J. (2001). The past sets the stage for the future: Follow-up issues facing long-term cancer survivors. Seminars in Oncology Nursing, 17(4), 263-267. doi:10.1053/sonu.2001.27921

Puetz, T.W., Morley, C.A., \& Herring, M.P. (2013). Effects of creative arts therapies on psychological symptoms and quality of life in patients with cancer. JAMA International Medicine, 173(11), 960969. doi:10.1001/jamainternmed.2013.836

Rieger, K., \& Schultz, A.S. (2014). Exploring arts-based knowledge translation: Sharing research findings through performing the patterns, rehearsing the results, staging the synthesis. Worldviews on Evidence-Based Nursing, 11(2), 133-139. doi:10.1111/wvn.12031

Rosedale, M. (2009). Survivor loneliness of women following breast cancer. Oncology Nursing Forum, 36(2), 175-183. doi:10.1188/09. ONF.175-183

Sinding, C., \& Wiernikowski, J. (2008). Disruption foreclosed: Older women's cancer narratives. Health, 12(3), 389-411. doi:10.1177/1363459308090055

Sonke, J., Rollins, J., Brandman, R., \& Graham-Pole, J. (2009). The state of the arts in healthcare in the United States. Arts \& Health, 1(2), 107-135. doi:10.1080/17533010903031580

Stuckey, H.L., \& Nobel, J. (2010). The connection between art, healing, and public health: A review of current literature. American Journal of Public Health, 100(2), 254-263. doi:10.2105/AJPH.2008.156497

The Institute of Medicine and National Research Council. (2005). From cancer patient to cancer survivor: Lost in transition. National Academies Press.

Thomas-MacLean, R. (2004a). Memories of treatment: The immediacy of breast cancer. Qualitative Health Research, 14(5), 628 643. doi:10.1177/1049732304263658

Thomas-MacLean, R. (2004b). Understanding breast cancer stories via Frank's narrative types. Social Science and Medicine, 58(9), 16471657. doi:10.1016/S0277-9536(03)00372-1

Thomas-MacLean, R. (2005). Beyond dichotomies of health and illness: Life after breast cancer. Nursing Inquiry, 12(3), 200-209.

Thompson, C.A., Stan, D.L., Solberg Nes, L., Jenkins, S.M., Lackore, K.A., \& Pruthi, S. (2014). Breast cancer survivors' self-reported needs and preferences of survivorship care. Breast Journal, 20(1), 107-109. doi:10.1111/tbj.12221

Thorne, S. (2008). Interpretive description (Vol. 2). Walnut Creek, CA: Left Coast Press Inc.

Visser, A., \& Op'T Hoog, M. (2008). Education of creative art therapy to cancer patients: Evaluation and effects. Journal of Cancer Education, 23(2), 80-84.

Waller, A., Groff, S.L., Hagen, N., Bultz, B.D., \& Carlson, L.E. (2012). Characterizing distress, the 6th vital sign in an oncology pain clinic. Current Oncology, 19(2), e53-59. doi:10.3747/co.19.882 